\title{
Effect of the Coriolis forces on dynamics of the system reservoir-liquid under uniform outflowing
}

\author{
Limarchenko O., Semenovych K. \\ Taras Shevchenko National University of Kyiv, \\ 4-E Academician Glushkov avenue, 01033, Kyiv, Ukraine
}

(Received 7 January 2018)

\begin{abstract}
A problem of motion of the cylindrical reservoir, partially filled with liquid, on pendulum suspension is considered in combined statement. The system motion occurs under the presence of uniform outflowing of liquid with the neglect of outflowing local effects. It was shown that the constructed mathematical model of the system describes the main mechanical effects and does not violate the conservation laws. Peculiarities the system dynamics under the presence of liquid outflowing are shown by the numerical examples of the system behavior for initial kinematic perturbation and under the external impulsive loading. Effect of the Coriolis forces in the development of wave motion on a liquid free surface under the presence of outflowing and for constant liquid volume is characterized. It was ascertained that the Coriolis forces promote the development of wave motion on a free surface of liquid, but suppress amplitudes of high-frequency normal modes.
\end{abstract}

Keywords: nonlinear dynamics of liquid, combined motion, inclined motion, outflowing, Coriolis forces.

2000 MSC: 76B07, 76B99

UDC: 532.595

DOI: $10.23939 / \mathrm{mmc} 2018.01 .034$

\section{Introduction}

Study of the effect of liquid outflowing on the development of dynamical processes in the system reservoir-liquid with a free surface is of great interest because the presence of liquid flow rate takes place in many cases of applications of structures with free-surface liquid. For example, we can mention transport of liquefied natural gas, radioactive waste, reservoirs for oil storage, fuel tanks of rockets, etc. Variable filling of the reservoir with liquid causes, in particular, a variation of normal frequencies in the system in the process of motion, which can cause potentially dangerous near-resonant dynamical processes. Some new features of the system behavior manifest due to the combination of outflowing and rotational motions of the reservoir.

\section{Mathematical model of the system reservoir-liquid on pendulum suspension}

For construction of the mathematical model of the motion of the system reservoir-liquid on pendulum suspension, we use the variation approach with further simplification of the continuum system of variables by means of the method of modal decomposition. The technique of construction of the resolving equations is described in detail in [1]. Statement of the problem of dynamics of the reservoir with liquid with a free surface includes the continuity condition for liquid flow in the considered bounded domain, boundary conditions on the surface of contact rigid body-liquid and the conditions on a free surface of the liquid. It is necessary to note that specification of the conditions on a free surface of the liquid is complicated since this surface is in advance unknown. 


$$
\begin{gathered}
\Delta \varphi=0, \quad \Delta \boldsymbol{\Omega}=0 \text { in } \tau ; \\
\frac{\partial \varphi_{0}}{\partial n}=0 \text { on } \Sigma ; \quad \frac{\partial \Omega}{\partial n}=0 \text { on } \Sigma+S_{0} ; \\
\frac{\partial \varphi_{0}}{\partial z}+\nabla \xi \cdot\left[\boldsymbol{\nabla} \varphi_{0}+\boldsymbol{\nabla}(\boldsymbol{\omega} \cdot \boldsymbol{\Omega})-\boldsymbol{\omega} \times \boldsymbol{r}\right]=\frac{\partial \varphi_{0}}{\partial z}+\boldsymbol{\omega} \cdot \frac{\partial \boldsymbol{\Omega}}{\partial z}-\left.(\boldsymbol{\omega} \times \boldsymbol{r})\right|_{z} \text { on } S_{\xi},
\end{gathered}
$$

where $\tau$ is the domain occupied by liquid; $S$ is a free surface of liquid; $\Sigma$ is a moisten surface of the reservoir. The Lagrange function function in the case of rotational motion of the reservoir has the following form

$$
\begin{aligned}
& L=\frac{1}{2} \rho \int_{\tau}[\boldsymbol{\nabla} \varphi+\boldsymbol{\nabla}(\boldsymbol{\omega} \cdot \boldsymbol{\Omega})]^{2} d \tau+\frac{1}{2} I_{r e s}^{i j} \omega_{i} \omega_{j}+\rho g\left(\cos \alpha_{1} \sin \alpha_{2} \cos \alpha_{3}-\sin \alpha_{1} \sin \alpha_{3}\right) \\
& \times \int_{S_{0}} r \cos \theta(\xi+H) d S-\rho g\left(\sin \alpha_{1} \cos \alpha_{3}+\cos \alpha_{1} \sin \alpha_{2} \sin \alpha_{3}\right) \int_{S_{0}} r \sin \theta(\xi+H) d S \\
&-\frac{1}{2} \rho g \cos \alpha_{1} \cos \alpha_{2} \int_{S_{0}} \xi^{2} d S-\left(M_{l} h_{l}+M_{r} h_{r}\right)\left(1-\cos \alpha_{1} \cos \alpha_{2}\right) \\
&-\sigma \int_{S_{0}} \sqrt{1+(\boldsymbol{\nabla} \xi)^{2}} d S-\sigma \cos \theta_{1} \int_{L_{0}} \xi d l+\boldsymbol{M} \cdot \boldsymbol{\chi}
\end{aligned}
$$

where $\rho$ is liquid density; $g$ is the free falling acceleration; $H$ is liquid filling in the reservoir; $M_{l}$, $M_{r}$ are masses of liquid and the reservoir; $h_{l}, h_{r}$ are displacements of mass centers of liquid and the reservoir relative to the plane of the undisturbed free surface of liquid; $\sigma$ is the coefficient of surface tension on a free surface of liquid; $I_{r e s}^{i j}$ is the inertia tensor of the reservoir, determined relative to the center of the undisturbed free surface $O ; \boldsymbol{M}$ is the main moment of external forces acting on the reservoir relative to the point $O ; \chi \chi$ is representation of turn angles of the reservoir relative to the immovable reference frame. Reference frames are constructed similar to [1]. For obtaining the motion equations of the system and dynamical boundary conditions we make use of the variational principle of the Hamilton-Ostrogradsky for the Lagrange function (4)

$$
\delta \int_{t_{1}}^{t_{2}} L d t=0
$$

Transition from the continuum system to its discrete model is performed by the method of modal decomposition with the use of the following representations of unknown variables

$$
\begin{gathered}
\xi=\sum_{n} a_{n}(t) \psi_{n}(x, y) ; \\
\varphi=\sum_{n} b_{n}(t) \psi_{n}(x, y) \frac{\cosh \varkappa_{n}(z+H)}{\varkappa_{n} \sinh \varkappa_{n} H} ; \\
\boldsymbol{\Omega}=\boldsymbol{\Omega}_{0}+\sum_{n} \boldsymbol{q}_{n}(t) \psi_{n}(x, y) \frac{\cosh \varkappa_{n}(z+H)}{\varkappa_{n} \sinh \varkappa_{n} H} .
\end{gathered}
$$

In these representations of unknowns the system of amplitude parameters $a_{n}(t), b_{n}(t), \boldsymbol{q}_{n}(t)$ are unknown variables of time $t$, and the functions $\psi_{n}(x, y), \boldsymbol{\Omega}_{0}$ are determined as the solutions of the following boundary value problems

$$
\Delta \psi_{n}+\varkappa_{n}^{2} \psi_{n}=0 \text { on } S_{0}, \quad \frac{\partial \psi_{n}}{\partial n}=0 \text { on } L_{0} ;
$$




$$
\Delta \boldsymbol{\Omega}_{0}=0 \text { in } \tau, \quad \frac{\partial \boldsymbol{\Omega}_{0}}{\partial \boldsymbol{n}}=\boldsymbol{r} \times \boldsymbol{n} \text { on } \Sigma+S_{0} .
$$

According to the theorem that vortex-free motion of ideal incompressible liquid is completely defined by motion of liquid boundaries the unknown variables $b_{n}(t), \boldsymbol{q}_{n}(t)$ are dependent and the variables $a_{n}(t)$ can be selected as the independent system of parameters, which number coincides with the number of degrees of freedom of liquid volume within the framework of the model, constructed on the basis of the modal decomposition approach. Elimination of the dependent variables was done according to the technique [1], and finally we can express the dependent parameters as

$$
b_{i}=b_{i}\left(a_{i}, \dot{a}_{j}\right) ; \quad \boldsymbol{q}_{n}=\boldsymbol{q}_{n}\left(a_{i}\right) .
$$

As it was above noted analytical holding the boundary conditions on a free surface of liquid represents considerable complexity. The used decompositions of variables are constructed such that they satisfy all kinematical boundary conditions besides the condition on a free surface exactly. Satisfying the nonlinear boundary condition on a free surface of liquid is done accurate to the third order of smallness (elevation of liquid is selected as the first order of smallness). After analytical elimination of the kinematical boundary condition on a free surface of liquid we pass to a free mechanical system in the parameters $a_{i}, \alpha_{i}$

$$
\sum_{n=1}^{N} p_{r n} \ddot{a}_{n}+\sum_{n=N+1}^{N+3} p_{r n} \ddot{\alpha}_{n-N}=q_{r}, r=\overline{1, N+3},
$$

where $p_{r n}$ is the quadratic matrix, $q_{r}$ is the vector of $N+3$ dimensionality. The system (12) consists of $N+3$ equations, where $N$ is the number of the considered normal modes of oscillations of a liquid free surface. Elements of the matrix and the vector depend on quadratures of normal modes of oscillations $\psi_{i}$ and the Stokes-Shukovsky vector potential, determined analytically for the cylindrical reservoir in [3]. Since we consider the case of immovable suspension point for description of the system motion we select the reference frame with the origin at this point, therefore, in this way we exclude from consideration translation motion of the system. The system of equation (12) is linear relative to the second derivatives of the desired variables. This premise enables transformation of the resolving system to the form suitable for use by the Runge-Kutta method.

\section{Dynamics of the system reservoir-liquid under uniform outflowing}

Let us consider the problem of combined motion of the cylindrical reservoir with free surfaced liquid on pendulum suspension, when uniform liquid outflowing according to the given law takes place. Here we do not consider local effects of outflowing, which corresponds to uniform outflowing through the bottom of the reservoir and is reduced only to change of the liquid filling depth according to the prescribed law $H=H_{0}+\Delta H \cdot t$, where $H_{0}$ is the initial filling level. Such assumptions are suitable for relative low outflowing velocities and comparatively large filling depths. Considering the local effects of outflowing was done, in particular, in [2] and, in general it is possible to take into account these effects within the framework of the the present approach too.

Since outflowing rate is supposed to be small, it is possible to simplify some expressions in the system motion equations, which contain $\Delta H$. The potential of simplification of such terms is caused by two main factors. First, outflowing rates are supposed to be small, second, the terms containing $\Delta H$ and time is inside the multiplier of $\tanh \varkappa_{n} H$ type and after time differentiation $\Delta H$ appears in the denominator in the form of the term $\cosh ^{2} \varkappa_{n} H \gg 1$, which rapidly increases with the increase of $H$. Let us consider transformation of the certain terms of the Lagrange equations. After transition to the discrete form of the Lagrange function we obtain 


$$
\begin{aligned}
L=\frac{1}{2} \sum_{i} \dot{a}_{i}^{2} \alpha_{i}^{v}+\frac{1}{2} \sum_{i, j, k} \gamma_{i, j, k}^{v}+\frac{1}{2} \sum_{i, j, k, l} \dot{a}_{i} \dot{a}_{j} a_{k} \delta_{i, j, k, l}^{v} & \\
& +\frac{1}{2} \sum_{p, s=1}^{3} \omega_{p} \omega_{s}\left(I_{r e s}^{p s}+A_{p s}^{2}+\sum_{i} a_{i} E_{p s i}^{2}+\sum_{i, j} a_{i} a_{j} E_{p s i j}^{2}\right) \\
& +\frac{1}{2} \sum_{p=1}^{3} \omega_{p}\left(\sum_{i} \dot{a}_{i} E_{p i}^{1 *}+\sum_{i, j} \dot{a}_{i} a_{j} E_{p i j}^{2 *}+\sum_{i, j, k} \dot{a}_{i} a_{j} E_{p i j k}^{3 *}\right) \\
+ & \rho g\left(\cos \alpha_{1} \sin \alpha_{1} \cos \alpha_{3}-\sin \alpha_{1} \sin \alpha_{3}\right)\left(\sum_{i} a_{i} \alpha_{i}^{c}+H l_{c}\right) \\
+ & \rho g\left(\sin \alpha_{1} \cos \alpha_{3}+\cos \alpha_{1} \sin \alpha_{2} \sin \alpha_{3}\right)\left(\sum_{i} a_{i} \alpha_{i}^{s}+H l_{c}\right) \\
-\frac{1}{2} \rho g & \cos \alpha_{1} \cos \alpha_{2} \sum_{i} a_{i}^{2} N_{i}-\sigma \cos \theta_{1} \sum_{i} a_{i} \lambda_{i}-\sigma S_{0}-\frac{\sigma}{2} \sum_{i} a_{i}^{2} \kappa_{i}^{2} N_{i} \\
& \quad+\frac{\sigma}{8} \sum_{i, j, k, l} a_{i} a_{j} a_{k} a_{l} \delta_{i j k l}^{4}-\left(M_{r} h_{r}+M_{l} h_{l}\right) g\left(1-\cos \alpha_{1} \cos \alpha_{2}\right)+\boldsymbol{M} \boldsymbol{\chi}
\end{aligned}
$$

Let us consider transition to the motion equations in the case of the presence of outflowing by the example of the first term of the Lagrange function. Here

$$
\alpha_{i}^{v}=\frac{N_{i}}{\varkappa_{n} \tanh \varkappa_{n} H(t)} ; \quad N_{i}=\int_{S} \psi_{i}^{2} d S
$$

The motion equation will include the two terms, where the second one is caused by liquid outflowing

$$
\frac{d}{d t} \frac{\partial L_{1}}{\partial \dot{a}_{i}}=\ddot{a}_{i} \alpha_{i}^{v}-\frac{\dot{a}_{i} N_{i} \varkappa_{i} \Delta H}{\varkappa_{i} \tanh ^{2}\left(\varkappa_{i} H(t)\right) \cosh ^{2} \varkappa_{i} H(t)} .
$$

Recalculation of coefficients of the motion equations is done according to the technique, given in [1] and depends upon the filling level of liquid. Under the condition of variable liquid filling it is necessary to perform recalculation of not only coefficients of the motion equations because of the change of $H$, but the length of pendulum suspension too. Since the origin of the reference frame fixed with the reservoir is at the center of the unperturbed free surface of liquid, the change of liquid filling affects the variation of the inertia tensor of the carrying body. Below recalculation of the model coefficients is done on every step of time integration and is stopped when $H<0.05 R$.

\section{Numerical examples}

Based on the constructed mathematical model we consider the problem about motion of the cylindrical reservoir with the radius $R=1 \mathrm{~m}$ on pendulum suspension of $l=R$ length, partially filled with ideal incompressible liquid. The reservoir mass amounts $10 \%$ of the liquid mass. We consider the case, when dissipation is absent. In the process of the system motion outflowing is performed according to the law $H=H_{0}+t \Delta H$, where $t$ is time, $H$ is liquid filling, scaled relative to the radius of the reservoir $R$ (index " 0 " corresponds to the initial state of liquid), $\Delta H$ is the rate of change of liquid level. Dynamics of the system is characterized by graphs of variation in time of dimensionless amplitudes of liquid level oscillations on the reservoir walls, amplitudes of oscillations of normal modes of liquid and the angle of deviation of the reservoir from the vertical position under the presence of outflowing (thin line) and for constant liquid volume (thick line). 


\subsection{Motion of the system under initial kinematic excitation}

At initial time instant the system is at the rest state, the reservoir is deflected from the equilibrium position by an angle $\alpha_{0}=\frac{\pi}{25}$. Before starting of the motion a free surface of liquid is horizontal. Therefore, at this position

$$
x_{3}=r \tan \alpha_{0}, \quad \text { where } \quad r=\sum_{i=1}^{3} a_{i} \breve{J}\left(\frac{\varkappa_{1}^{(i)} r}{R}\right) ; \quad a_{i}=\frac{\int_{0}^{R} r^{2} \breve{J}\left(\frac{\varkappa_{1}^{(i)} r}{R}\right) d r}{\int_{0}^{R} \breve{J}^{2}\left(\frac{\varkappa_{1}^{(i)} r}{R}\right) d r} .
$$

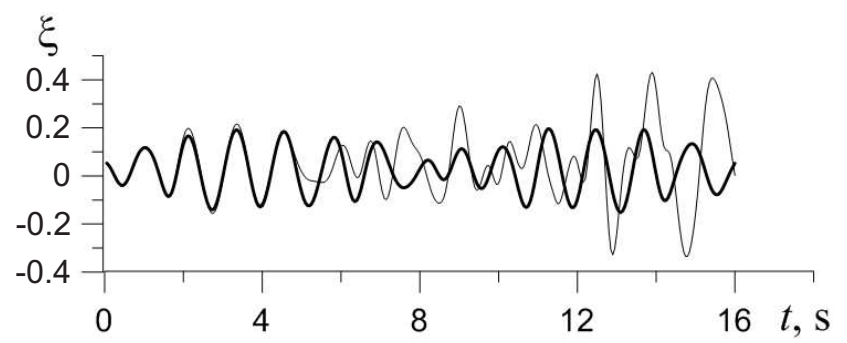

Fig. 1. Amplitude of oscillations of a free surface on the reservoir walls.

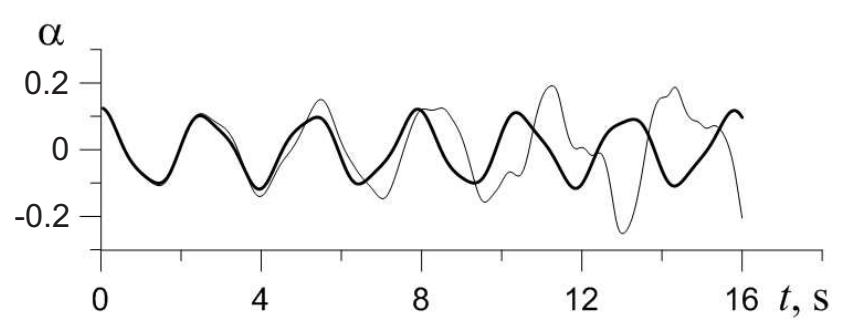

Fig. 3. Variation in time of deflection angle of the reservoir from the vertical direction.

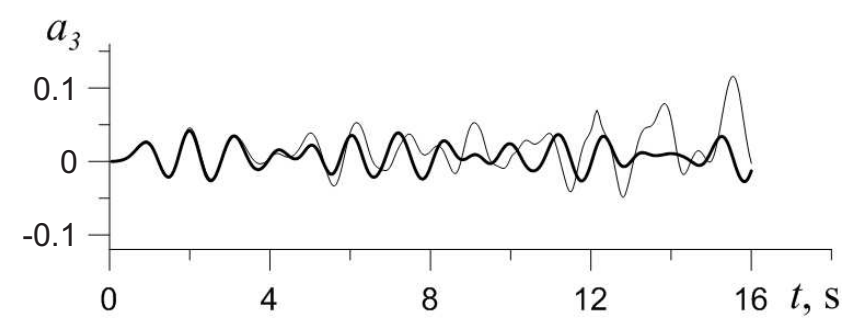

Fig. 2. Amplitude of oscillations of the axisymmetric mode of liquid.

Numerical results were obtained for the outflowing rate magnitude $\Delta H=-0.05$. As it is seen from Fig. 3 under the presence of outflowing in the course of time the increase of amplitude and the decrease of frequency of the reservoir oscillations take place, which is in accord with theorem about variation of momentum. Amplitudes of oscillations of liquid also increase. Dynamics of the system is considerably nonlinear, which manifests by comparatively large values of the increase of amplitudes of axisymmetric normal modes of liquid oscillations (Fig.2) in comparison with the problem with constant volume of liquid.

\subsection{Motion of the system under external impulsive loading}

Let us consider the problem about the system motion under the action of external torque in the form of rectangular impulse of $1 \mathrm{~s}$ duration. The impulse amplitude was selected such that oscillations of liquid free surface hit nonlinear range of perturbations. Outflowing rate was accepted as $\Delta H=-0.02$.

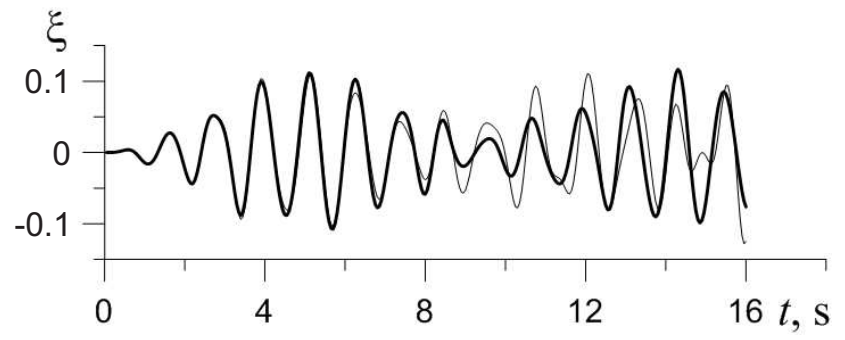

Fig. 4. Amplitude of liquid elevations on tank walls.

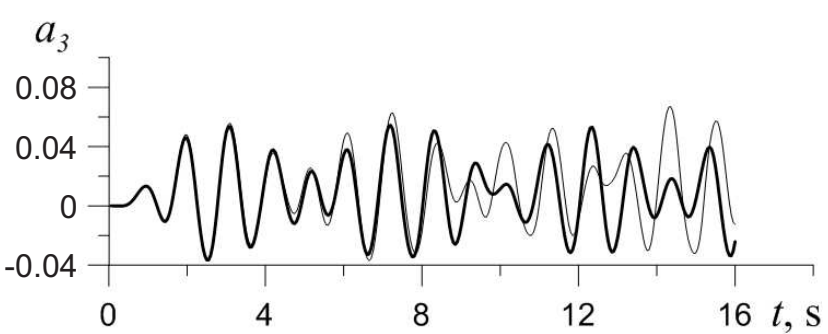

Fig. 5. Amplitude of the axisymmetric mode of liquid. 
It follows from comparison of variation in time of amplitudes of axisymmetrical normal modes in Figs. 2, 5 that for torque disturbance of motion manifestation of nonlinearities is stronger than in the case of kinematical perturbation of motion. At the same time for toeque disturbance of the system motion amplitudes of the axisymmetric normal modes in the vase of the presence of outflowing and without it practically coincide.

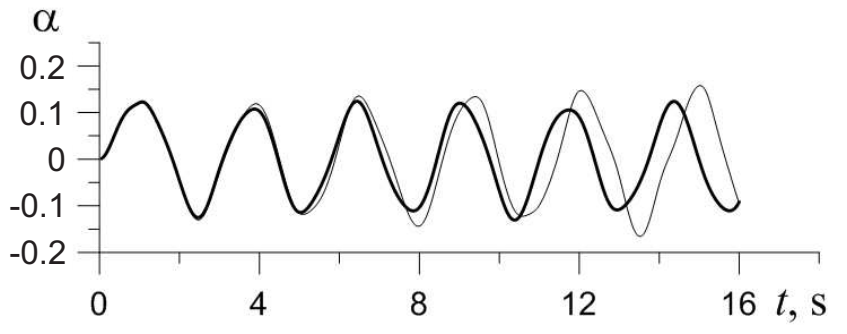

Fig. 6. Variation in time of angular deflection of the reservoir from vertical direction.

\section{Effect of the Coriolis forces on wave motion on a free surface of liquid}

For studying the impact of the Coriolis forces we consider the problem of kinematic excitation of liquid motion in the reservoir on pendulum suspension with and without taking into account the Coriolis forces. These forcers appear in the motion equations due to the presence of terms of the the third row in the Lagrange function (13). Neglect of the Coriolis forces results in the decrease of liquid elevation of a free surface.

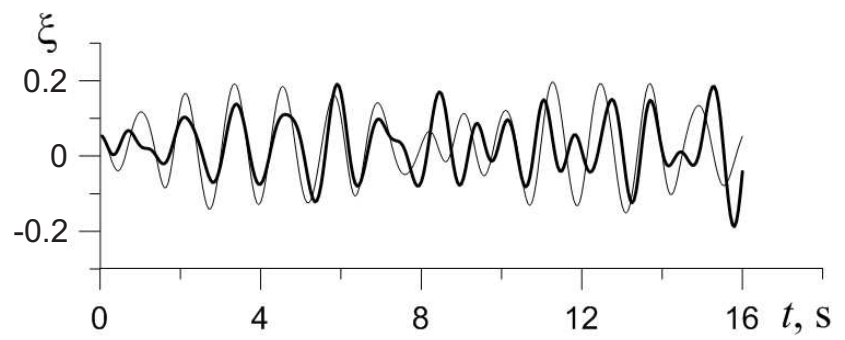

Fig. 7. Amplitude of liquid free surface on tank walls in the case of constant volume of liquid.

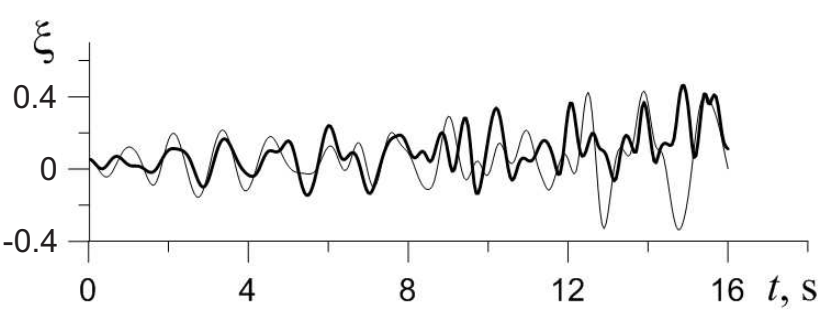

Fig. 8. Amplitude of liquid free surface on tank walls in the case of uniform outflowing.

Figs. 7, 8 show dynamics of oscillations of liquid free surface on the reservoir walls (thick line corresponds to the neglect of the coriolis forces).

Table 1. Maximal absolute values of the system motion paramerters.

\begin{tabular}{|c|c|c|c|c|}
\hline $\begin{array}{c}\text { Parameter of } \\
\text { the system } \\
\text { motion }\end{array}$ & $\begin{array}{c}\text { Problem with } \\
\text { constant } \\
\text { volume of liquid }\end{array}$ & $\begin{array}{c}\text { Problem with constant } \\
\text { volume of liquid (without } \\
\text { the Coriolis forces) }\end{array}$ & $\begin{array}{c}\text { Problem } \\
\text { with uniform } \\
\text { outflowing }\end{array}$ & $\begin{array}{c}\text { Problem with uniform } \\
\text { outflowing (without the } \\
\text { Coriolis forces) }\end{array}$ \\
\hline$a_{2}$ & 0.11266 & 0.07396 & 0.25935 & 0.17396 \\
$a_{3}$ & 0.04187 & 0.02663 & 0.11611 & 0.1154 \\
$a_{10}$ & 0.01718 & 0.09722 & 0.14261 & 0.12881 \\
$a_{12}$ & 0.00723 & 0.00867 & 0.05781 & 0.07059 \\
$\xi$ & 0.19604 & 0.19089 & 0.43178 & 0.46243 \\
$\alpha$ & 0.12422 & 0.12422 & 0.25154 & 0.25265 \\
\hline
\end{tabular}

Contribution of the Coriolis forces in the development of wave processes on a liquid free surface and energy redistribution in the problem with liquid outflowing and without it is shown in Table 1 . The presence of the Coriolis forces promote energy redistribution between low-frequency and high-frequency modes. In particular, in the case of the absence of the Coriolis forces decrease of the maximum value of the amplitude of axisymmetric normal mode decreases by one and a half times. At the same time amplitudes of high antisymmetric modes increase.

In the case of liquid outflowing the effect of the Coriolis forces on development of nonlinear mechanisms and energy redistribution manifests weaker, since the effect of liquid outflowing has greater contribution in formation of dynamical processes. 
Thus, the analysis of numerical results showed neglect of the mechanism of the Coriolis forces leads to the reduction of amplitudes of oscillations of a free surface, which manifests stronger in the case of liquid outflowing. So, the Coriolis forces promotes the increase of amplitudes oscillations of a liquid free surface and suppress oscillations of high-frequency modes.

\title{
6. Conclusions
}

The nonlinear model of dynamics of combined motion of the system reservoir-liquid with a free surface is constructed in the case of the presence of liquid uniform outflowing. Efficiency of the model is confirmed by numerical examples of the system motion. The problems of systems dynamics for initial deviation of the reservoir form the equilibrium position and under the action of external impulsive loading were analyzed from the point of view of the effect of liquid outflowing on the excitation of liquid sloshing. Special attention is paid to the contribution of the Coriolis forces on energy redistribution between amplitudes of oscillations of normal modes. It was ascertained that liquid outflowing promotes manifestation of nonlinear mechanisms of processes development. It was shown also that the obtained results are in accord with conservation laws of mechanics.

[1] Limarchenko O. S., Yasinskiy V. V. Nonlinear dynamics of structures with liquid. National Technical University of Ukraine "KPI", Kyiv (1997).

[2] Maksimenko A. L. Investigation of nonlinear modes of motion of bounded liquid volume of variable mass with a free surface. Ph. D. Thesis Phys. \& Math. (1987).

[3] Abgaryan K. A., Rappoport I. M. Dynamics of rockets. Mashinostroenie, Moscow (1969).

\section{Вплив сил Коріоліса на динаміку системи резервуар-рідина за рівномірного витікання}

\author{
Лимарченко О., Семенович К. \\ Київсъкий начіональний університет імені Тараса Шевченка, \\ пр. акад. Глушкова, 4-Е, 01033, Київ, Украӥна
}

\begin{abstract}
Розглянуто задачу про рух циліндричного резервуару, частково заповненого рідиною, на маятниковому підвісі в сумісній постановці. Під час руху системи відбувається рівномірне витікання рідини, локальними ефектами витікання знехтувано. Показано, що побудована математична модель системи описує основні механічні ефекти і не суперечить законам збереження. Особливості динаміки системи за наявності витікання проілюстровано чисельними прикладами руху системи в разі початкового кінематичного відхилення та під дією зовнішнього імпульсного навантаження. Вивчено внесок сил Коріоліса в розвиток хвильового руху на вільній поверхні рідини за наявності витікання і проведено порівняння із задачею зі сталим об'ємом рідини. Встановлено, що Коріолісові сили сприяють розвитку хвильового руху на вільній поверхні рідини, проте пригнічують високочастотні форми коливань.
\end{abstract}

Ключові слова: нелінійна динаміка рідини, вільна поверхня, сумісний рух, кутовий рух, витікання, сиди Коріоліса.

2000 MSC: 76B07, 76B99

УдК: 532.595

Mathematical Modeling and Computing, Vol.5, No. 1, pp. 34-40 (2018) 